\title{
Accounting for Regulatory Distance and Looking for the Most Potential Indonesia's FTA/CEPA Partners
}

\author{
Ernawati Munadi \\ Business and Economic Faculty \\ Wijaya Kusuma University \\ Surabaya, Indonesia \\ ernamu@yahoo.com
}

\author{
Ayu Sinta Saputri \\ Center For Foreign Trade Policy \\ Ministry of Trade \\ Jakarta, Indonesia \\ ayu.sinta@kemendag.go.id
}

\begin{abstract}
As tariff is declining, Non-Tariff Measures (NTMs) become significantly important to supercede tariff role in protecting domestic industry. To overcome the negative impact of NTMs, some countries, including Indonesia, have been actively developing economic cooperations, so does . This study seeks to identify the most potential FTA/CEPA partners for Indonesia, from regulatory distance (RD) perspective. The study utilizes regulatory distance analysis on 11 Indonesian CEPA/FTA partners which are selected from certain criteria. Analysis shows that the regulatory distance between Indonesia and its main FTA/CEPA partners is small, it is between 0.003 0.132. The most potential Indonesia's FTA/CEPA partners are from ASEAN countries such as Malaysia, Singapore, Thailand, and Vietnam. While the most potential partners from outside ASEAN countries are Pakistan and the USA. This is indicated by the similarity of NTM patterns at the product level as resulted from the regulatory distance analysis. It reveals a sort of common pattern of NTM regimes. Moreover, the results reveal that Indonesian regulatory structure is relatively different from the Philippines and Australia and these countries tend to be outlier. The regulatory structure of Japan, EU and Korea is relatively closer to Indonesia. Therefore, it is important for Indonesia to address NTMs issues when negoatiating its economic cooperation, in particular with Australia and the Philippines, through Mutual Recognition Agreement and Harmonisation of Standard.
\end{abstract}

Keywords- Non-Tariff Measures (NTMs); Regulatory Distance Analysis; Free Trade Agreement

\section{INTRODUCTION}

The use of non-tariff policies which is well-known as Non-Tariff Measures (NTMs) has increased significantly along with the declining of tariff to protect domestic industry. Compared with tariff, NTMs is less transparent due to many reasons.

In the broad spectrum, NTMs is defined as all trade policy other than traditional tariff measures that will potentially affect trade through price, quantity or both. NTMs is classified as technical measures, such as Sanitary and phytosanitary (SPS), Technical Barrier to trade (TBT) and Pre-shipment Inspection (PSI), to non-technical measures such as price and quantity control, threat measures (e.g. antidumping and safeguards), and trade-related finance and investment measures. (Ing et all (2016)).

Unlike tariff, NTMs data are not expressed as numerical values but often expressed as complex pieces of regulations.
It requires big efforts, is time consuming and costly in identifying them. They are not clearly stated in relevant regulations, and could only be found by reading the regulations carefully. NTMs is fragmented and spread over a large number of government agencies which have different mandates. In common practice it can be distributed to over ten different agencies with personnel who are unlikely to have common knowledge and understanding about NTMs. The externalities would not be taken into account in national decision making, and therefore outcome wouldn't be optimal. This condition is made worst with the weak coordination among government agencies responsible on issuing NTM regulations. It is not uncommon that the process of drafting the regulations is not inclusive, the implementation is not clear, and the mechanism to review the regulations in a regular basis does not exist, and consequently this affect business negatively. To overcome the negative impact of the implementation of NTMs policies, many countries in the world, including Indonesia, developed economic cooperation through bilateral and/or regional cooperation. This is due to the fact that NTMs has dual personality. In one hand, NTMs has been confirmed affecting trade costs. On the other hand the presence of NTMs can be potentially as a source of deeper regional/international integration. Some studies that are lookingfrom this perspective are Cadot and Ing (2015) and Ven (2016).

Up to 2015, Indonesia has developed eight economic cooperation through regional cooperation within the framework of ASEAN and bilateral cooperation. Some of those cooperations are in the form of Comprehensive Economic Partnership Agreement (CEPA) and few other are as Free Trade Agreement (FTA). This study tries to further examine the NTMs policy applied by Indonesia and the main FTA/CEPA partner countries. Some research questions are: does a "core" of similar regulatory structures within Indonesia and its main FTA/CEPA exist?, if so, which countries diverge from it? In which industries are regulatory patterns already well harmonized and which ones are lagging behind, and for which country pairs? What products are potential to be included in the policy harmonization between Indonesia and the main FTA/CEPA countries? 


\section{INDONESIA FTA/CEPA}

Economic cooperation agreements in the world have developed rapidly since the 1990s. According to the WTO, in 1991 there were only 5 trade cooperation agreements notified to GATT. The number increased significantly and reached its peak in 2004. On average cooperation agreement notified to the WTO after 1992-2016 amounted to 27 . Summing up to 2015, there were 625 trade cooperation agreements that had been notified to GATT and WTO.

Indonesia is not in a country list that aggressively establishes trade cooperation. Up to 2015, Indonesia is incorporated into eight international trade agreements, six of which are regional agreements, while another two are bilateral agreements. All regional agreements followed by Indonesia are within the framework of ASEAN, namely the ASEAN Free Trade Area (AFTA); ASEAN-Australia and New Zealand FTA; ASEAN-China FTA; ASEAN-India FTA; ASEAN-Japan FTA; ASEAN-Korea FTA. The two bilateral agreements signed by Indonesia were the Indonesia-Japan Economic Partnership Agreement (IJEPA) and Indonesia-Pakistan PTA.

The number of trade cooperation agreements that Indonesia has followed is still lagging behind the main ASEAN countries. Malaysia has seven bilateral trade agreements, Vietnam has five bilateral trade agreements, while Singapore has thirteen bilateral agreements. This bilateral agreement includes agreements with major world markets such as the European Union, China and the United States. Besides bilateral agreements these countries also participate in regional agreements under the ASEAN framework. This means that ASEAN countries whose international trade structure is not much different from Indonesia has greater international market access than Indonesia.

Indonesia's lack of aggressiveness in opening up new markets through international agreements has begun to have a negative impact. Indonesia began to lose its traditional markets for several main products to rival countries in the ASEAN region. For example, CPO exports from Malaysia began to undermine the Indonesian CPO market in India, Pakistan and the European Union. Likewise, with clothing, footwear and wood products from Vietnam. In the past year Indonesia began to be more aggressive in opening new trade agreements. Several trade negotiations whose processes were halted began to be reactivated including trade agreements with the European Union, Australia, Chile, India, Iran, South Korea and Turkey. Indonesia also seriously considered accessing the TPP back in 2018.

\section{RESEARCH METHODOLOGY}

\section{A. Regulatory Distance (RD)}

The Regulatory distance analysis used in this paper exactly follows the analysis used by Cadot, et. all (2015) and Cadot et all (2018) to calculate the distance of regulatory structure between Indonesia and its main CEPA/FTA Partners. Some other research that used the same method to calculate the regulatory distance in his research are Cadot and Ing (2015) and Melo and Nicita (2018). The regulatory distance index measures the distance on the regulatory structure as the difference between the patterns in which two countries impose NTMs, classified according to the
UNCTAD-MAST nomenclature, across products. In principle, the index investigates on whether two countries apply the same NTM types to the same products. Calculating regulatory distance is carried out within two steps.

Step 1. identify the similarity of NTMs-regulation structure used by pair countries. Suppose that country $i$ imposes NTM $l$ on product $k$. If country j also imposes NTM $l$ on product $k$, we conclude that, for the given measureproduct pair, countries $i$ and $j$ have a "similar" regulatory structure and code our regulatory distance variable as zero. If, by contrast, country j does not impose NTM $l$ on product $k$ but imposes either no NTM or instead, say, NTM $g$, we say $i$ and $j$ are "different" for that measure product pair and code the regulatory distance variable as one. Formally, let i index countries, k HS6 products and j NTM types, and let

$$
n_{\text {ilk }}=\left\{\begin{array}{l}
1 \text { if country } i \text { applies NTMs lto product } k \\
0 \text { otherwise }
\end{array}\right.
$$

be a "dummy" (binary) variable marking the application of NTM type 1 by country $\mathrm{i}$ on product $\mathrm{k}$. The regulatory distance measure at the measure-product level is then

$$
R D_{i k}=\left|n_{i l k}-n_{j l k}\right|
$$

Step 2. Aggregation of the regulatory distance variable over all measures and all products (several thousand cells) to get an overall measure of dissimilarity. Formalizing again definition, let $\mathrm{N}$ be the total number of observed productNTM combinations. The distance in regulatory structures between countries $\mathrm{i}$ and $\mathrm{j}$, Dij is

$$
D_{i j}=\frac{1}{N} \Sigma_{k} \Sigma_{l}\left|n_{i l k}-n_{j l k}\right|
$$

that is, the sum of the absolute values of the differences in NTM application status. As the individual terms $\mathrm{RD}_{\mathrm{lk}}$ are either zero (when a given NTM is applied by both $\mathrm{i}$ and $\mathrm{j}$ to the same product) or one (when one of the two countries applies a measure that the other does not to a given product).

Calculating RD will provide understanding on whether CEPA/AFTA partner countries and Indonesia has regulatory dissimilarity. The smaller the $\mathrm{RD}$ index the greater the similarity of the types of NTMs used by Indonesia and FTA/CEPA partner countries. Conversely, the greater RD indicator the greater the regulatory structure difference between NTMs used by Indonesia and its main CEPA/TFA partners.

The regulatory distance then indicates the percentage at which the combinations of product-NTMs in two countries are not the same. Lower index indicates the more similar regulatory framework of the two countries. Similar to other incidence indicators, RD can be calculated at the sector level and for certain types or groups of NTM.

Regulatory distance can easily be disaggregated to a product or sector level as the used approach has high flexibility. Comparisons can be made between two or more 
countries, or entire PTAs or regional groups can be benchmarked against each other. The assessment can also focus on specific groups of NTMs only.

\section{B. Data and Analysis}

The research uses trade and NTMs data which is downloaded using the World Integrated Trade Solution (WITS).

\section{RESUlt AND Discussion}

\section{A. Regulatory Distance across countries}

The value of the regulatory distance is usually represented in a small number as RD is normaliseed by the grand total of product -NTM combinations, in practice the index lies between zero and one. In our sample, it ranges from 0.003 and 0.132 . This result is in line with other research findings. Cadot, et all (2015) for example found that the RD value range is 0.009 between Madagascar and the United Republic of Tanzania, and 0.304 between China and Nepal.

Figure 1 shows the average RD between Indonesia and its peers, the main CEPA/FTA Partners and the ranking. On average RD with the Philippines is the highest at 0.068 (lowest is closer), implying that the regulatory structure between Indonesia and the Philippines is relatively different from its other peers. Meanwhile, CEPA/FTA partners with the least regulatory distance if put in order is Pakistan, Singapore, Thailand, Malaysia, and Japan. Figure 1 reveals that Indonesian regulatory distance is relatively wider with developed countries, such as Australia, South Korea, EU28, and Japan. It is relatively closer among developing countries except for the Philippines. However, it does not mean trade with countries with least regulatory distance will encourage more trade.

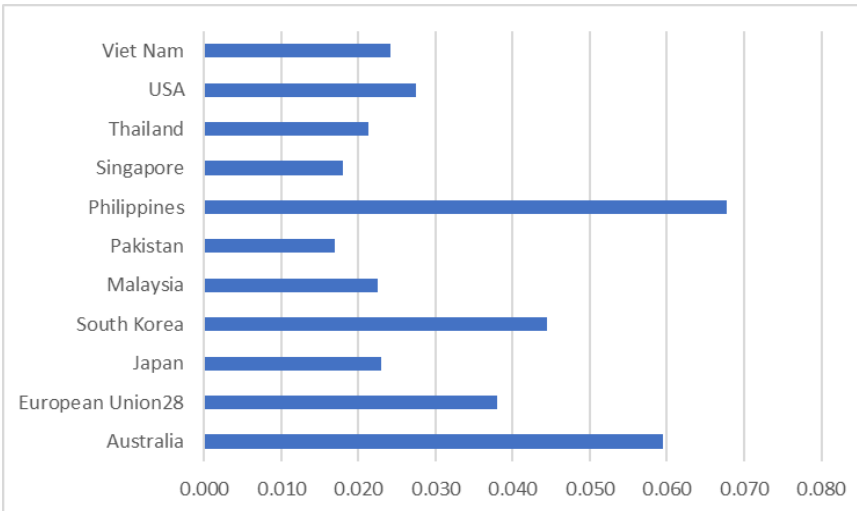

Source: World Integrated Trade Solution database, analysed

Fig. 1. The average of regulatory distance, Indonesia and its peers

Ven (2017) argued that some concerns have been raised about the implication of regulatory distances of NTM regimes on trade. However, he confirmed that there is no empirical study on the effects of regulatory distance on trade. Therefore, there is not enough empirical evidence to assert that closer regulatory distance associates with more trade or wider regulatory distance associates with less trade.

Cadot et al., (2015) did further analysis from the regulatory distance perspective to understand the impact of regulatory reform on RTA. He concluded that RTAs induce a convergence of regulatory structures; that is, member States tend to apply the same type of measures to the same products. However, he also emphasized that the process should greatly facilitate further in-depth harmonization within measure types, that is, convergence in the level of stringency of the measures.

From this perspective, a closer regulatory distance may make it easier for countries with RTA to have an MRA and harmonise their NTMs regimes. Countries having similar NTMs, might only need small changes to harmonize their NTMs. However, two countries that implement the same NTMs on a commodity do not necessarily mean their NTMs can be harmonised. Unless both countries recognize each other's testing or certification, the exporters must have their commodities tested and certified by the regulatory body in the importing country. If both countries have harmonized their standards and regulations or have mutual recognition agreement (MRA) related to the commodities, the exporters would be only required to conduct test or certification one time.

Figure 2 shows a new and alternative way of representing regulatory distance. The idea is to project bilateral distances onto a plane akin to a map. In order to interpret the figure, note that the axes are arbitrary: they are scaled so as to fit the range of bilateral distances and merely represent the cardinal points in which distances are mapped (Cadot, et all (2015)). Figure 2, shows the results for the overall NTM database, suggests several observations.

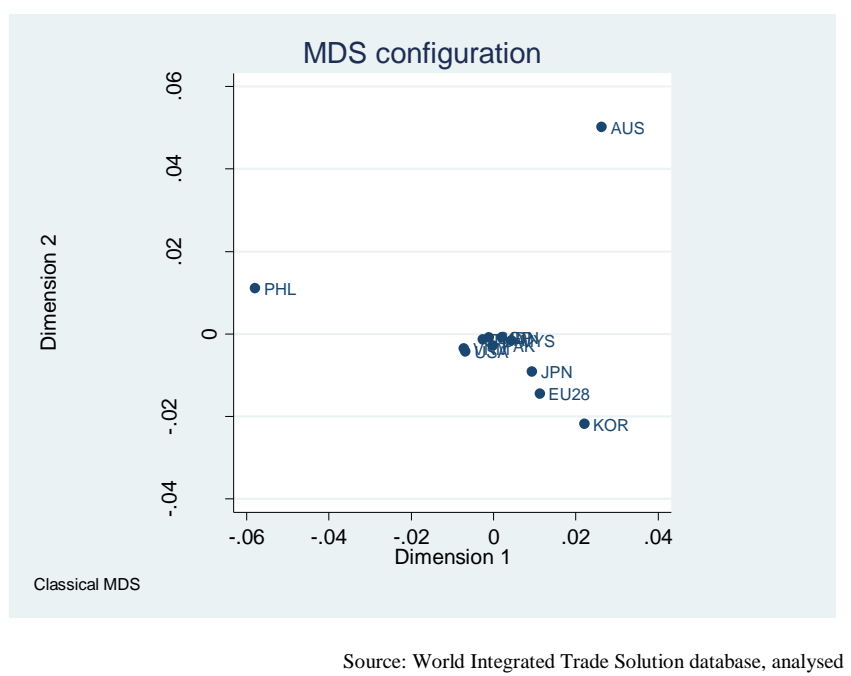

Fig. 2. The Regulatory Distance of Indonesian and Its main FTA/CEPA Trading Partners, all products

First, on overall products, the finding reveals that there is a "core" of countries with similar NTM patterns at the product level, providing a sort of common pattern of NTM regimes.

Second, Australia and the Philippines do indeed stand out the most from the group. It implies that both countries relatively have dissimilarity on NTMs regulation structure compared with the other nine countries.

This finding implies that from NTMs perspective on products, Pakistan is the most potential country for Indonesia 
to have deeper regional integration is. As from the regulatory distance perspective both countries are very similar, therefore it will be easier for both countries to harmonize their standards and regulations or to have mutual recognition agreement (MRA) on their interests.

\section{B. Regulatory Distance across Products Group}

Figure 3 presents the regulatory distance across products group. The two digits HS code was classified into 19 different product groups. Figure 2 reveals that the highest regulatory distance between Indonesia and its peers are on agricultural products, namely on animal \& animal products, animal products, vegetables products, and animal or vegetables fats and oils. For other than agricultural products, said manufacturing products, the regulatory distance is relatively lower.

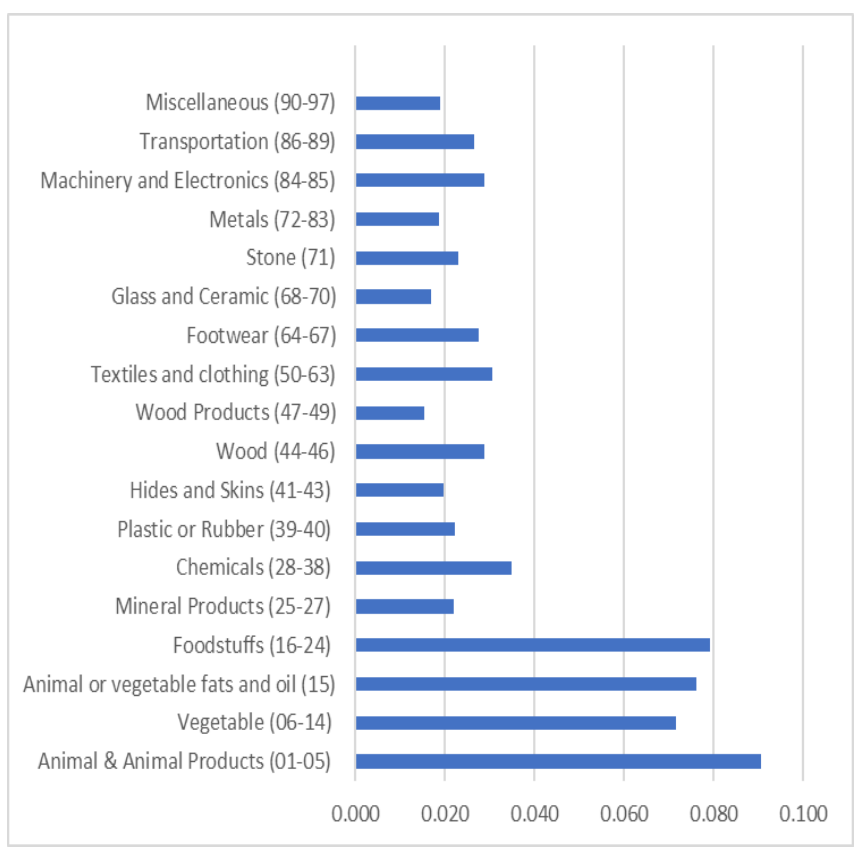

Source: World Integrated Trade Solution database, analysed

Fig. 3. The average regulatory distance between Indonesia and its peers, by product groups

This finding implies that Indonesian regulatory structure dissimilarity on agricultural products are relatively higher than on manufacturing products. Therefore, it will be easier for those countries to harmonize their standards and regulations or to have mutual recognition agreement (MRA) on their interests.

Table I and II present the regulatory distance of products groups by country to identify potential productsfor harmonization and be included in the mutual recognition. The smaller the the regulatory distance figure is, the more potential is the product. The two-digit HS code was classified into 19 different product groups. The table can provide an illustration if Indonesia wants to identify which products are potentials to be included in the harmonisation policy and mutual recognition arrangement strategy with its CEPA/TFA partners. For example, the animal product group (01-05) with EU28, Singapore, and Viet Nam. Similarly, the animal or vegetables fats and oils products with Pakistan, Japan, Malaysia, and Singapore as their regulatory structure is relatively similar with Indonesia compared with other countries.
TABLE I. THE REGULATORY DISTANCE OF INDONESIA AND ITS PEERS, BY PRODUCT GROUPS

\begin{tabular}{|c|c|c|c|c|c|c|c|c|c|c|c|}
\hline Cuntries & $01-05$ & 06-14 & 15 & $16-24$ & $25-27$ & $28-38$ & $39-40$ & $41-43$ & $44-46$ & $47-49$ & $50-63$ \\
\hline Australia & 0.09 & 0.10 & 0.11 & 0.12 & 0.05 & 0.06 & 0.05 & 0.04 & 0.05 & 0.05 & 0.06 \\
\hline European Union28 & 0.07 & 0.11 & 0.10 & 0.08 & 0.02 & 0.04 & 0.03 & 0.03 & 0.03 & 0.03 & 0.04 \\
\hline Japan & 0.08 & 0.05 & 0.04 & 0.06 & 0.02 & 0.05 & 0.02 & 0.02 & 0.01 & 0.01 & 0.02 \\
\hline South Korea & 0.12 & 0.11 & 0.13 & 0.12 & 0.02 & 0.08 & 0.05 & 0.02 & 0.04 & 0.01 & 0.02 \\
\hline Malaysia & 0.10 & 0.06 & 0.05 & 0.06 & 0.01 & 0.01 & 0.01 & 0.02 & 0.02 & 0.00 & 0.02 \\
\hline Pakistan & 0.08 & 0.04 & 0.02 & 0.05 & 0.00 & 0.01 & 0.01 & 0.01 & 0.01 & 0.00 & 0.02 \\
\hline Philippines & 0.11 & 0.10 & 0.11 & 0.10 & 0.08 & 0.06 & 0.05 & 0.05 & 0.10 & 0.04 & 0.05 \\
\hline Singapore & 0.07 & 0.04 & 0.05 & 0.05 & 0.01 & 0.02 & 0.01 & 0.01 & 0.01 & 0.00 & 0.02 \\
\hline Thailand & 0.08 & 0.06 & 0.09 & 0.08 & 0.01 & 0.02 & 0.01 & 0.01 & 0.01 & 0.00 & 0.02 \\
\hline USA & 0.12 & 0.08 & 0.07 & 0.08 & 0.01 & 0.02 & 0.02 & 0.01 & 0.02 & 0.00 & 0.03 \\
\hline Viet Nam & 0.07 & 0.05 & 0.06 & 0.06 & 0.01 & 0.02 & 0.01 & 0.01 & 0.02 & 0.01 & 0.03 \\
\hline
\end{tabular}

TABLE II. THE REGULATORY DISTANCE OF INDONESIA AND ITS PEERS, BY PRODUCT GROUPS

\begin{tabular}{|l|c|c|c|c|c|c|c|c|c|c|c|}
\hline Cuntries & $64-67$ & $68-70$ & 71 & $72-83$ & $84-85$ & $86-89$ & $90-91$ & 92 & 93 & $94-96$ & 97 \\
\hline Australia & 0.05 & 0.05 & 0.05 & 0.05 & 0.05 & 0.07 & 0.05 & 0.04 & 0.05 & 0.05 & 0.04 \\
\hline European Union28 & 0.04 & 0.02 & 0.01 & 0.02 & 0.04 & 0.03 & 0.04 & 0.01 & 0.01 & 0.02 & 0.01 \\
\hline Japan & 0.02 & 0.01 & 0.01 & 0.01 & 0.03 & 0.02 & 0.02 & 0.01 & 0.01 & 0.01 & 0.00 \\
\hline South Korea & 0.02 & 0.02 & 0.03 & 0.02 & 0.05 & 0.03 & 0.04 & 0.02 & 0.02 & 0.02 & 0.00 \\
\hline Malaysia & 0.02 & 0.01 & 0.01 & 0.01 & 0.01 & 0.01 & 0.01 & 0.02 & 0.02 & 0.01 & 0.01 \\
\hline Pakistan & 0.02 & 0.01 & 0.03 & 0.01 & 0.01 & 0.01 & 0.01 & 0.01 & 0.01 & 0.01 & 0.00 \\
\hline Philippines & 0.06 & 0.05 & 0.07 & 0.05 & 0.07 & 0.06 & 0.05 & 0.05 & 0.07 & 0.05 & 0.04 \\
\hline Singapore & 0.02 & 0.01 & 0.01 & 0.01 & 0.01 & 0.02 & 0.01 & 0.00 & 0.01 & 0.01 & 0.00 \\
\hline Thailand & 0.02 & 0.01 & 0.01 & 0.01 & 0.01 & 0.01 & 0.01 & 0.00 & 0.01 & 0.00 & 0.00 \\
\hline USA & 0.02 & 0.01 & 0.01 & 0.01 & 0.01 & 0.03 & 0.02 & 0.01 & 0.01 & 0.01 & 0.00 \\
\hline Viet Nam & 0.02 & 0.01 & 0.01 & 0.02 & 0.02 & 0.02 & 0.01 & 0.01 & 0.02 & 0.01 & 0.02 \\
\hline
\end{tabular}

However, it should also be realized that the regulatory distance analysis does not take into account the regulatory stringency. Therefore, the results of analysis should be treated with care and should not be used to indicate whether the NTMs policies are inhibiting or not. In order to reach this conclusion, further analysis must be made regarding the regulatory stringency whose analysis is more technical and deepens the conditions in the same types of NTMs.

\section{CONCLUSION AND RECOMMENDATION}

They are several important points derived from this study, and summarized as follows: First, the value of regulatory distance in this study is between 0.003 and 0.132 , and the finding reveals that there is a "core" of countries with similar NTM patterns at the product level that provides a sort of common pattern of NTM regimes.

The most potential Indonesia's FTA/CEPA partners are ASEAN countries such as Malaysia, Singapore, Thailand, and Vietnam. While outside of ASEAN countries, they are Pakistan and the USA. The similarityof the regulatory distance and NTM patterns between Indonesia and these countries are encouraging factors to harmonize and have mutual recognition agreement.

The analysis from the regulatory distance also shows that Australia and the Philippines stand out from the above group, implying that they relatively have dissimilarity on NTMs regulation structure with Indonesia. Even though, it might be in reality it will be easier to penetrate the Philippines and Australia market for Indonesia relative to US market. As 
trade flows within countries is influenced by many factors and NTMs is only small part of them. However, it is then important for Indonesia to address NTMs issues when negoatiating its economic cooperation, through the agreement on Mutual Recognition and Harmonisation of Standard.

\section{ACKNOWLEDGMENT}

The author is grateful to the Ministry of Trade (MOT). Special thanks to the MOT's Research Department (BP3) at the Ministry of Trade for organising this International Conference, which provides opportunity for the authorsto produce this publication. Special thanks is also given to Scientific committee for their comments during the writing process.

\section{REFERENCES}

[1] Cadot, O., and Ing, L.Y., "Non-tariff Measures and Harmonisation: Issues for the RCEP”, ERIA Discussion Paper Series, ERIA-DP2015-61.

[2] Ing, L.Y., S.F. Cordoba, and O. Cadot, "Non-Tariff Measures in $A S E A N$ ". Book chapter. Jakarta: Economic Research Institute for
ASEAN and East Asia and United Nations Conference on Trade and Development, 2016

[3] World Integrated Trade Solution, http://wits.worldbank.org/WITS/WITS/Default-A.aspx?Page=Default (accessed 17 February 2019).

[4] Cadot, O., M.J. Ferrantino, J. Gourdon, and J.D. Reyes, "Reforming Non-Tariff Measures: From Evidence to Policy Advice". Washington, DC: The World Bank Group, 2018.

[5] Melo, J. and A. Nicita (2018), 'Non-tariff measures: data and analytical tools', in Non-Tariff Measures: Economic Assessment and Policy Options for Development. Paris: United Nations Conference on Trade and Development

[6] Cadot., O., Asprilla, A., Gourdon, J., Knebel, C., and Peters, R. "Deep Regional Integration and Non-Tariff Measures: A Methodology For Data Analysis", Policy Issues In International Trade And Commodities, Research Study Series No. 69, The United Nations Conference on Trade and Development (UNCTAD), 2015.

[7] Ven, S., "Exploring Non-Tariff Measures Facing The Fisheries Trade in ASEAN: The Case of Cambodia Cambodia Development Resource Institute (CDRI). https://www.researchgate.net/publication/320491091_Exploring_Non Tariff_Measures_Facing_The_Fisheries_Trade_in_ASEAN_The_Cas e of Cambodia (accessed on January 2019) 